\title{
S/CAR '90 Symposium on Computer-Assisted Radiology
}

\author{
Anaheim, CA, June 13-16, 1990
}

$\mathbf{T}^{\mathrm{H}}$ HE SOCIETY for Computer Applications in Radiology (SCAR) and the organizing committee for Computer Assisted Radiology (CAR) are sponsoring the upcoming Symposium on Computer Assisted Radiology, S/CAR '90, to be held June 13-16, 1990 in Anaheim, CA. This conference will be the merger between two highly successful series of prior meetings. This symposium will be the 10th Conference on Computer Applications in Radiology, previously sponsored by the American College of Radiology and the Radiology Information Systems Consortium. This symposium will also be the fourth Conference on Computer Assisted Radiology, previously sponsored by CAR in Europe.

S/CAR '90 has been organized to cover the spectrum of computer applications in radiology, with a special focus on each day of the meeting. Issues related to the effective utilization of computing will be addressed for improving the clinical practice of radiology, advancing biomedical science, and managing health-care resources. These topics should appeal to a broad audience of health care and computing professionals.

S/CAR '90 will present tutorials and workshops that are quite similar to the popular format of the Ninth Conference on Computer Applications in Radiology at Hilton Head in June 1988. Papers will be presented in two parallel sessions, as in previous CAR meetings, to provide material of interest to both clinical and technical attendees.

On Wednesday, June 13, Management Information Systems will be featured. As on all days of the conference, the morning session will begin with a tutorial, in this case presented by Ronald L. Arenson, MD and R. Gilbert Jost, MD. This tutorial will be followed by a general paper session for all attendees. After the coffee break, two parallel paper sessions will be held, as will occur in the afternoon sessions. Teleradiology, Artificial Intelligence, and Reporting Systems will be the themes for sessions in addition to the RIS sessions. The early evening will feature four workshops, each given twice (attendees choose two of these, based on availability). The work- shops include:

Expert Systems for Radiology with Henry A. Swett, MD, Paul R. Fisher, MD, and Pradeep G. Mutalik

The Storage and Transmission of Medical Images with $\mathrm{Al}$ Griebenow and Sridhar B. Seshadri, MSEE

3-D Image Reconstruction with Gabor $\mathrm{T}$. Herman, PhD and Michael W. Vannier, MD

Planning for PACS with Carl E. Ravin, MD

Thursday, June 14 will be devoted to Picture Archive and Communication Systems. The morning will begin with the tutorial, by H.K. Huang, $\mathrm{PhD}$ and Heinz U. Lemke, $\mathrm{PhD}$, followed by the paper sessions, similar in format to the previous day. In the afternoon, attendees will be able to choose between two different panel discussions concerning the implementation of PACS.

Friday, June 15 will focus on various aspects of image processing with sessions devoted to computer vision, graphics, and tomographic reconstruction. The tutorial will be lead by George Seeley, PhD and Michael Rhodes, PhD. Workshops in the early evening will include:

Radiologic Workstations with R. Gilbert Jost, MD

ACR/NEMA Standard with Steven C. Horii, MD

Computer-based Teaching with Robert A. Greenes, MD, PhD

Digital Image Compression with H.K. Huang, PhD

Saturday, June 16, will be a half day only, concentrating on teaching and research applications. The tutorial on Teaching and Decision Support will be lead by Henry A. Swett, MD, and Robert A. Greenes, MD, PhD. One session will present papers on education while another will focus primarily on research in magnetic resonance imaging, related to computer applications, of course.

To date, there are 24 commercial exhibits signed up with several more planned if we can find the space. Lunch will be served daily in the exhibit hall to facilitate access to these worthy exhibits. 
The Organizing committee consists of the following:

Course Director: Ronald L. Arenson, MD

Course Codirector: Richard M. Friedenberg, MD

Scientific Session Cochairmen:

Clinical: Ronald L. Arenson, MD and Richard M. Friedenberg, MD

Technical: Roger A. Bauman, MD and Jack Sklansky, PhD

Tutorial Cochairmen: R. Gilbert Jost, MD and Michael Rhodes, PhD

Workshop Cochairmen: Robert M. Allman, MD and Henry A. Swett, MD
Technical Exhibits Chairman: Richard M. Friedenberg, MD

International Coordinator: Heinz U. Lemke, $\mathrm{PhD}$

Meeting Planner: Ms Janis Ford

Full programs will be mailed out in February. If for some reason you do not receive a copy, please call the Program Director, Ronald L. Arenson, MD, at 215-662-3032. Over 200 individuals have already indicated their intention in attending, even without seeing the program! So, make your plans now for S/CAR '90, Anaheim, June 13-16, 1990. 